\title{
Neuronal Development in the Larvae of the Invasive Biofouler Dreissena polymorpha (Mollusca: Bivalvia), with Special Attention to Sensory Elements and Swimming Behavior
}

\author{
IZABELLA BATTONYAI ${ }^{1, *,}$, ELENA E. VORONEZHSKAYA ${ }^{2, \dagger}$, ALEXANDRA OBUKHOVA $^{2}$, \\ RÉKA HORVÁTH ${ }^{1}$, LEONID P. NEZLIN ${ }^{2}$, AND KÁROLY ELEKES ${ }^{1}$ \\ ${ }^{1}$ Department of Experimental Zoology, Balaton Limnological Institute, MTA Centre for Ecological \\ Research, Hungarian Academy of Sciences, Klebelsberg Kuno u.3, H-8237 Tihany, Hungary; and ${ }^{2}$ Institute \\ of Developmental Biology, Russian Academy of Sciences, Vavilov Str. 26, Moscow 117808, Russia
}

\begin{abstract}
Although understanding of the neuronal development of Trochozoa has progressed recently, little attention has been paid to freshwater bivalves, including species with a strong ecological impact, such as the zebra mussel (Dreissena polymorpha). Therefore, an important question might concern how the developing nervous system is involved in the formation of the rapid and successful invasive behavior of this species. Our aim was to reveal the neuronal development of trochophore and veliger larvae of Dreissena, with special attention to the organization of sensory structures and their possible involvement in detecting environmental cues. After applying serotonin and FMRFamide immunocytochemistry, the first serotonin immunoreactive sensory elements appeared 16-18 hours after fertilization, whereas the first FMRFamide immunoreactive sensory cell was seen only at 32 hours of development (trochophore stage). Later, sensory elements were found in three parts of the larval body, including the apical
\end{abstract}

Received 12 December 2017; Accepted 26 April 2018; Published online 18 June 2018.

* To whom correspondence should be addressed. E-mail: battonyai.izabella@ okologia.mta.hu.

$\dagger$ These authors contributed equally.

Correction: This article was reposted on June 22, 2018, to correct an error in the grant number.

Abbreviations: 5-HT, serotonin; 5-HTP, 5-hydroxytryptophan; AO, apical organ; DAPI, 4',6-diamidino-2-phenylindole; EDTA, ethylenediaminetetraacetic acid; FMRFa, FMRFamide; FW, filtered water; hpf, hours postfertilization; IHC, immunohistochemical; IR, immunoreactive; PBS, phosphate-buffered saline; PBS-TX-NGS, PBS containing 1\% Triton X-100 and 10\% normal goat serum; pCPA, para-chlorophenilalanine; PFA, paraformaldehyde; $\mathrm{PN}$, posterior neuron. organ, the posterior region, and the stomach. Although differences in the timing of appearance and the morphology of cells were observed, the two signaling systems showed basic similarity in their organization pattern until the end of the veliger stage. Pharmacological, physiological, and quantitative immunocytochemical investigations were also performed, suggesting the involvement of both the serotoninergic system and the FMRFamidergic system in sensomotor processes. Manipulation of the serotonin synthesis by para-chloroplenylalanine and 5-hydroxytryptophane, as well as application of increased salinity, influenced larval swimming activity, both accompanied by changes in immunofluorescence intensity. We concluded that these two early sensory systems may play an important role in the development of settlement competency of this biofouling invasive bivalve, Dreissena.

\section{Introduction}

Invasive dreissenid bivalves impart a strong ecological and economic threat in ecosystems (Aldridge et al., 2008). They have invaded a variety of habitats outside their native range and expanded rapidly in both European and North American lakes and rivers (Claudi and Gerald, 1994; Bobeldyk et al., 2005). With their rapid invasion, dreissenids can quickly colonize new areas, causing serious fouling problems by altering the stability of the original ecosystem in different ways, including the suppression of native bivalve species (Mackie, 1991; O'Neill, 1997; Lovell et al., 2006). The zebra mussel (Dreissena polymorpha), which is native in the Caspian Sea region, appeared in Hungary in the early 1930s in Lake Balaton, the larg- 
est shallow lake in Europe (Entz and Sebestyén, 1942); and within a few years it completely invaded the lake and became the ruling bivalve in it.

Early developmental stages are generally accepted as a critical and determining period of the mussel (bivalve) life cycle (He et al., 2015). Zebra mussel life history is similar to that of marine bivalves and differs from that of the indigenous freshwater molluscan fauna. Namely, it begins with fertilization and spiral cleavage but is then followed by extracapsular development of free-swimming trochophore larvae, appearing 6 hours after fertilization and existing for a total of 32 hours before entering the next veliger larval stage (Sprung, 1993; Ackerman et al., 1994).

Bivalve larvae display a broad repertoire of behavioral patterns mediated by early elements of the nervous system, first by peripheral sensory cells (Kempf et al., 1997). Since the common ancestor of all Trochozoa likely possessed a trochophore larva, the group has been the longtime focus of extensive comparative anatomical, systematic, evolutionary, and phylogenetic studies (Naef, 1928; Beklemishev, 1969; Ruppert and Barnes, 1994; Haszprunar et al., 1995; Nielsen, 1995, 1998). Recently, efforts have been made to understand the neuronal development in the trochophore stage of different molluscan species (Wanninger and Haszprunar, 2003; Kristof and Klussmann-Kolb, 2005; Voronezhskaya et al., 2008). Studies on molluscan larvae have revealed that they already possess a rather well-developed nervous system, including, in general, the cerebral and pedal ganglia and, most importantly, the apical organ (AO), a specific sensory structure that exists until the end of embryogenesis (Barlow and Truman, 1992; Kempf et al., 1992, 1997; Voronezhskaya and Elekes, 1993; Hay-Schmidt, 1995; Croll, 2000; Dickinson et al., 2000; Page, 2002; Voronezhskaya et al., 2002, 2003; Hadfield, 2011). The AO seems to participate in detecting environmental cues, including unfavorable conditions, and so initiates behavioral changes in the animals (Hadfield et al., 2000; Voronezhskaya et al., 2004; Hadfield, 2011; Glebov et al., 2014). Whether early sensory elements other than $\mathrm{AO}$ are also present and involved in the regulation of the embryonic development and behavior of molluscs has not yet been examined. In contrast to gastropod and polyplacophoran molluscs, a few studies have been aimed at the early neuronal development of bivalves (Da Costa et al., 2008; Aranda-Burgos et al., 2014; He et al., 2015). Analyzing the early developmental stages may also be important from a comparative aspect, because bivalves are considered to be more closely related phylogenetically to gastropods than to polyplacophorans (Taylor, 1996).

Morphological characteristics of the developing nervous system of molluscs, mostly gastropods, at the level of the individual neuronal elements, have been described by using antibodies raised against various neurotransmitters and neuromodulators, combined with the application of different immunohistochemical (IHC) techniques (Croll and Voronezhskaya,
1996; Elekes et al., 1996; Diefenbach et al., 1998; Voronezhskaya et al., 1999; Croll, 2000, 2006; Hegedüs et al., 2004). Serotonin (5-HT) and FMRFamide (FMRFa) occupy a prominent place among the signal molecules that are involved in a number of regulatory processes at both cellular and systems levels in adult and developing molluscs (see, e.g., Walker, 1986; Walker et al., 1996; Croll, 2000; Hay-Schmidt, 2000; López-Vera et al., 2008; and, e.g., Diefenbach et al., 1991; Vitellario-Zucarello et al., 1991; Voronezhskaya and Elekes, 1996, 2003; Marois and Carew, 1997; Page and Parries, 2000; Leise et al., 2001; Croll and Dickinson, 2004; Newcombe et al., 2006). Serotonin has already been detected in molluscan oocytes (Buznikov, 2007; Ivashkin et al., 2012, 2015), and both 5-HT-immunoreactive (IR) and FMRFa-IR neurons have been found to appear as early as in trochophore larvae (Croll, 2000; Voronezhskaya and Croll, 2016). Early trochophore FMFRa-IR neurons have been suggested to be pioneer cells that form a scaffold along which the central ganglia develop later (Croll and Voronezhskaya, 1995, 1996).

The aim of our study was to analyze the early, trochophore, and veliger larval development of the nervous system of the biofouling bivalve Dreissena polymorpha (Dreissenidae, Bivalvia, Mollusca). We paid special attention to sensory elements and their transmitter content, combined with physiological (swimming) assays, in order to understand their organizational principles. These principles may thus determine larval behavior, and may be possibly involved in the successful invasive capability of this species. Namely, the proper and early sensation and processing of environmental cues may be important factors that lead to the species' quick and broad dispersal and settlement. To follow the neurodevelopmental events in Dreissena larvae, we applied multiple fluorescence IHC labeling of 5-HT- and FMRFa-containing sensory elements. Then, in the physiological assays, either combined with 5-HTergic pharmacological interventions or by mimicking altered environmental conditions through increased salinity, we followed the upward swimming response of 48-hour postfertilization (hpf) veliger larvae.

\section{Materials and Methods}

\section{Animals}

Adult specimens of the zebra mussel, Dreissena polymorpha (Pallas, 1771), were collected in Lake Balaton (Hungary) during late May-June 2014-2016. The 12-15-mm-long specimens were gently removed from rock substrates by cutting their byssus threads. Animals were then held in running aerated lake water at $20-22{ }^{\circ} \mathrm{C}$. Prior to the spawning procedure, each mussel was quickly cleaned with $70 \%$ ethanol. Spawning was induced by a combination of thermal shock (Dyachuk and Odintsova, 2009) and subsequent incubation with fluoxetine (Fong, 1998). Fifty animals were placed in a small beaker containing 0.5 liters of filtered Lake Balaton 
water $(\mathrm{FW})$ and were kept at $10{ }^{\circ} \mathrm{C}$ for $12 \mathrm{~h}$. Thereafter, mussels were placed individually in vessels filled with $10 \mathrm{ml}$ of FW containing $5 \mu \mathrm{mol} 1^{-1}$ fluoxetine at $23{ }^{\circ} \mathrm{C}$. To maintain a constant temperature for 15-30 $\mathrm{min}$, the vessels were placed in a large petri dish filled with $23{ }^{\circ} \mathrm{C}$ water. Males started to spawn after about $30 \mathrm{~min}$, whereas females began after $1 \mathrm{~h}$ of incubation. Spawning individuals were immediately moved into 50-ml vessels filled with fresh FW.

Eggs originating from several females were collected after 30 min of spawning and placed in a 800-ml beaker containing $100 \mathrm{ml}$ of FW. Then five or six drops of FW containing sperm obtained from one male individual were added and stirred gently. After $20 \mathrm{~min}$ of fertilization, the upper $50 \mathrm{ml}$ of water was removed, and $500 \mathrm{ml}$ of fresh FW was carefully added to the beaker. The cleavage process and subsequent larval development were followed under an Axioplan compound light microscope (Carl Zeiss, Oberkochen, Germany).

Fertilized eggs were maintained in $800-\mathrm{ml}$ beakers at $22^{\circ} \mathrm{C}$ to develop further. After 14-16 h, the hatched larvae were collected from the upper one-third of the water column and transferred into fresh FW containing $50 \mu \mathrm{mol}{ }^{-1}$ neomycin (neomycin sulfate, Sigma, St. Louis, MO), to prevent bacterial contamination during subsequent larval development. Larvae developed further in $500 \mathrm{ml}$ of FW under constant agitation of the water column by an air jet directed to the water surface.

To examine the development of the nervous system, we collected samples at the following stages: blastula (16 hpf); early, middle, and late trochophore (18 and $22 \mathrm{hpf}, 28 \mathrm{hpf}$, and 32-36 hpf, respectively); and early, middle, and late veliger (40-48 hpf, 60 hpf, and 96 hpf, respectively).

\section{Immunochemistry}

Larvae were placed in $7 \% \mathrm{MgCl}_{2}$ diluted in $\mathrm{FW}$ for $30 \mathrm{~min}$ at $10{ }^{\circ} \mathrm{C}$. Animals were then fixed in $4 \%$ paraformaldehyde diluted in $0.1 \mathrm{~mol} \mathrm{l}^{-1}$ phosphate-buffered saline (PBS, $\mathrm{pH}$ 7.4) for $6 \mathrm{~h}$ at $4{ }^{\circ} \mathrm{C}$ and rinsed five times in $0.1 \mathrm{~mol} \mathrm{l}^{-1}$ PBS overnight. Then larvae were put into PBS containing $0.1 \mathrm{~mol} \mathrm{l}^{-1}$ ethylenediaminetetraacetic acid (EDTA) for $30 \mathrm{~min}$ at room temperature, to remove calcium from the developing shells. After thorough washing, samples were incubated with polyclonal anti-5-HT or anti-FMRFamide primary antibodies raised in rabbit (ImmunoStar, Hudson, WI, dilution 1:2000), in both instances together with monoclonal mouse anti-acetylated $\alpha$-tubulin (Sigma, dilution $1: 3000)$. All antibodies were diluted in $0.1 \mathrm{~mol}^{-1}$ PBS containing $1 \%$ Triton X-100 and 10\% normal goat serum (PBSTX-NGS). Incubation with primary antibodies lasted 24-48 h at $4{ }^{\circ} \mathrm{C}$. After rinsing, the specimens were incubated overnight at $4{ }^{\circ} \mathrm{C}$ in a mixture of $1: 1000$ dilution of Alexa Fluor 488 goat anti-rabbit immunoglobulin $\mathrm{G}$ (for both 5-HT and FMRFamide detection; Molecular Probes, Eugene, OR) and Alexa Fluor 633 goat anti-mouse (for tubulin detection; Molecular Probes), both diluted in $0.1 \mathrm{~mol} \mathrm{l}^{-1}$ PBS-TX. Specimens were then washed three times in PBS, each for 15 min; stained with $0.1 \mu \mathrm{g} \mathrm{ml}^{-1} 4^{\prime}, 6$-diamidino-2-phenylindole (DAPI) (Sigma) diluted in PBS, in order to visualize the nuclei; washed again in PBS for $15 \mathrm{~min}$; and, finally, immersed in $80 \%$ glycerol diluted with PBS. The specimens in the small vials were placed in a dark box and left in a refrigerator for three or four weeks for clearing, and then they were mounted on glass slides. At least 50 embryos of each stage were examined for both 5HT and FMRFa immunostaining. The specificity of the antibodies used in our study has been documented previously in various molluscs (Hernádi et al., 1989; Kemenes et al., 1989; Voronezhskaya and Elekes, 1996; Moroz et al., 1997), including bivalves (Dickinson et al., 2000; Voronezhskaya et al., 2008; Dyachuk and Odintsova, 2009). Negative controls obtained by omitting the primary antibodies revealed no specific immunostaining.

All samples were viewed by using either an epifluorescent Keyence BZ-9000 microscope (Nikon, Minoto, Tokyo, Japan) or a Leica TCS SP8 confocal laser scanning microscope (Leica, Wetzlar, Germany), with appropriate wavelength filter configuration settings. The necessary number of optical sections (20-60) with a $0.5-0.7-\mu \mathrm{m}$ step size were made to capture all of the visualized details. Subsequent reconstructions of full-depth images using Nikon or Leica software were applied. The schemes, graphs, and photos were combined into plates, using Adobe Photoshop CS (San Jose, CA). Only the brightness and contrast of the images were adjusted, if necessary.

Immunochemically detected fluorescence intensity has been shown to correlate well with the transmitter content of the nerve cell (Voronezhskaya et al., 2004; Ivashkin et al., 2015). In our experiments, 48-hpf veliger larvae were processed for immunostaining protocol and then used for quantification of relative fluorescence intensity. All samples were investigated under a Leica TCS SP8 confocal laser scanning microscope, using standard configuration settings. The fluorescence intensity of 5-HT-IR and FMRFa-IR elements was determined for individual embryos $(n=20$ for each data point). Each element was manually bordered, and average pixel intensity was detected inside the border in arbitrary fluorescence units (a.u.). Measurements and analysis were performed by using FIJI software (Schindelin et al., 2012). Statistical analysis and graphs were made using GraphPad Prism (LaJolla, CA). The obtained data were compared for control and experimental groups by using nonparametric MannWhitney $U$ tests.

\section{Swimming activity assay}

The experimental setup was assembled with two plastic syringes (each of 3-ml volume, with 10-mm diameter and 50-mm length), placed onto each other by their narrow ends and tightly connected via a narrow plastic tube. The upper 
syringe was filled with FW. Two milliliters of incubation solution containing 48-hpf veliger larvae taken from the respective experimental group (about 200-300 animals $\mathrm{ml}^{-1}$ ) was transferred into the lower syringe. The upper and lower syringes were then tightly connected to each other by plastic tubing, and the whole experimental setup was positioned vertically in a quiet, nonvibrating, shaded place for $30 \mathrm{~min}$ at $22{ }^{\circ} \mathrm{C}$. After $30 \mathrm{~min}$, the upper and lower syringes were gently detached, and FW containing larvae from the upper and lower syringes was collected in 3-ml test tubes. The larvae were then fixed with $4 \%$ paraformaldehyde (PFA) diluted in $0.1 \mathrm{~mol} \mathrm{l}^{-1} \mathrm{PBS}$ and were counted under a stereo dissecting microscope. Data were compared for control and experimental groups by using nonparametric Mann-Whitney $U$ tests.

To test the effect of para-chlorophenilalanine (pCPA, Sigma), a 5-HT synthesis inhibitor, 48-hpf veligers were maintained in $50 \mathrm{ml}$ of FW containing $10^{-5} \mathrm{~mol} 1^{-1} \mathrm{pCPA}$ for $6 \mathrm{~h}$ at $22^{\circ} \mathrm{C}$. To test the effect of 5-hydroxytryptophan (5-HTP, Sigma), a 5-HT synthesis precursor, 48-hpf veligers were maintained in $50 \mathrm{ml}$ of FW containing $10^{-5} \mathrm{~mol} \mathrm{l}^{-1} 5$-HTP for $1 \mathrm{~h}$ at $22{ }^{\circ} \mathrm{C}$. After incubations, the 48 -hpf larvae were processed for the swimming assay, followed by quantitative immunochemical analysis. To test the response of the larvae to increased salinity, $2 \mathrm{~g}$ of $\mathrm{NaCl}(2 \%)$ was added to 1 liter of $\mathrm{FW}$, and larvae were then cultivated from $24 \mathrm{hpf}$ to $48 \mathrm{hpf}$. The tested $2 \%$ o salinity is within the highest concentration measured in Lake Balaton (Somlyódi et al., 1983). After incubations, the larvae were processed for the swimming assay, followed by quantitative immunochemical analysis.

\section{Results}

\section{Development of the 5-HT immunoreactive system}

The first 5-HT-IR neuron appeared in the blastula stage (16 hpf). It was located at the center of the upper part, was about $5 \mu \mathrm{m} \times 8 \mu \mathrm{m}$ in size, and bore two long cilia (Figs. 1a, d, 2). Two hours later (18 hpf), in early trochophore larva, the 5HT-IR cell displayed a flask-shaped form, with a short, thick dendrite at the apical part projecting toward the surface (Figs. 1b, 2). In addition, a second 5-HT-IR neuron of similar morphology was seen closely adjacent to the first one (Fig. 1b, inset). In 22-hpf larvae, a small, rudimentary neuropil was also visible near the two cells, indicating the developing AO (Figs. 1c, 2). At the same trochophore stage, a 5-HT-IR unpaired bipolar posterior neuron ( $\mathrm{PN}$ ) appeared asymmetrically at the left-side posterior extreme of the larval body (Fig. 1c). No connection was detected between the anterior and posterior 5-HT-IR neurons at this stage. From the early trochophore stage (18 hpf), the ciliated prototroch started to be transformed into the velum (22 hpf), the main larval swimming organ (Fig. 1c).

At the early veliger stage (40 hpf), the 5-HT-IR neurons at the apical extreme of the body displayed an elongated flask- shaped form, with a short and thick dendrite bearing two long cilia, by which they reached the surface at the apical region (Figs. 1d, 2). A third labeled flask-shaped nonciliated neuron appeared dorsally to the first two apical cells, and two more without sensory dendrites were located laterally adjacent to the flask-shaped AO neurons (Figs. 1e, f, 2). At 48 hpf, a thick, bright neurite projected from the midline of the $\mathrm{AO}$ to the anterior adductor muscle (Figs. 1i, 2).

At $40-48 \mathrm{hpf}$, a robust distal dendrite of the PN, with two long cilia connected to the dendritic knob, was constantly detected (Figs. 1g-j, 2). On the opposite end of the PN, two thin varicose axon processes projected symmetrically on the left and right sides to the AO (Figs. 1g-i, 2). The PN thereafter retained this anatomy throughout, until the end of the investigated larval development ( $96 \mathrm{hpf}$ ), that is, possessing axon processes reaching the anterior part of the body and a thick, short ciliated dendrite projecting distally to the caudal surface of the animal (Fig. 2). In addition, from $40 \mathrm{hpf}$, two more tubulin-IR cells were seen adjacent to the PN (Fig. 1j, $\mathrm{k}$, insets). These three cells seemed to be part of a possible posterior sensory organ, probably functioning with 5-HT and other neurotransmitters.

By $40 \mathrm{hpf}$ of the early veliger stage, the digestive system was already formed, and the stomach was clearly visible. At this time, a 5-HT-IR cell with a typical pear-like form appeared in the stomach wall (Figs. 1j, k, 2). Labeled processes originating from the stomach neuron could also be observed. By $40 \mathrm{hpf}$, the short, thick dendrite projected straight toward the stomach lumen. From the 48-hpf early veliger stage, a long axon process, bearing varicosities along its entire length, ran anteriorly to the $\mathrm{AO}$, following the stomach curvature (Fig. 1j, j'). By the late (96-hpf) veliger stage, the AO comprised a compact neuronal structure, including a neuropil; together with the other two sensory elements (the PN and the stomach cell) bearing long axon processes, they seem to represent the larval sensory system of Dreissena (Fig. 2). The main larval swimming organ, the velum, displayed a significant increase in size during veliger development (40-96 hpf), although without receiving any 5-HT-IR innervation (Fig. 1g, $\mathrm{h}, \mathrm{k})$.

\section{Development of the FMRFamide-immunoreactive system}

The very first FMRFamide-IR (FMRFa-IR) neuron appeared in the late trochophore stage ( $32 \mathrm{hpf}$ ) at the anterior extreme of the larval body, at the site of the developing AO (Figs. 3a, 4). The solitary cell displayed a flask-shaped form, with a short, thick dendrite projecting to the surface, without bearing sensory cilia. The apical tuft of cilia was clearly identifiable nearby. By the early veliger stage ( $40 \mathrm{hpf}$ ), a total of seven Fa-IR cells were already present in the larval body, delineating the future organization of neuronal elements up to the end of the veliger stage (96 hpf) (Figs. 3b, 4). In the apical extreme of the body, one more labeled cell with weak fluorescence appeared that 


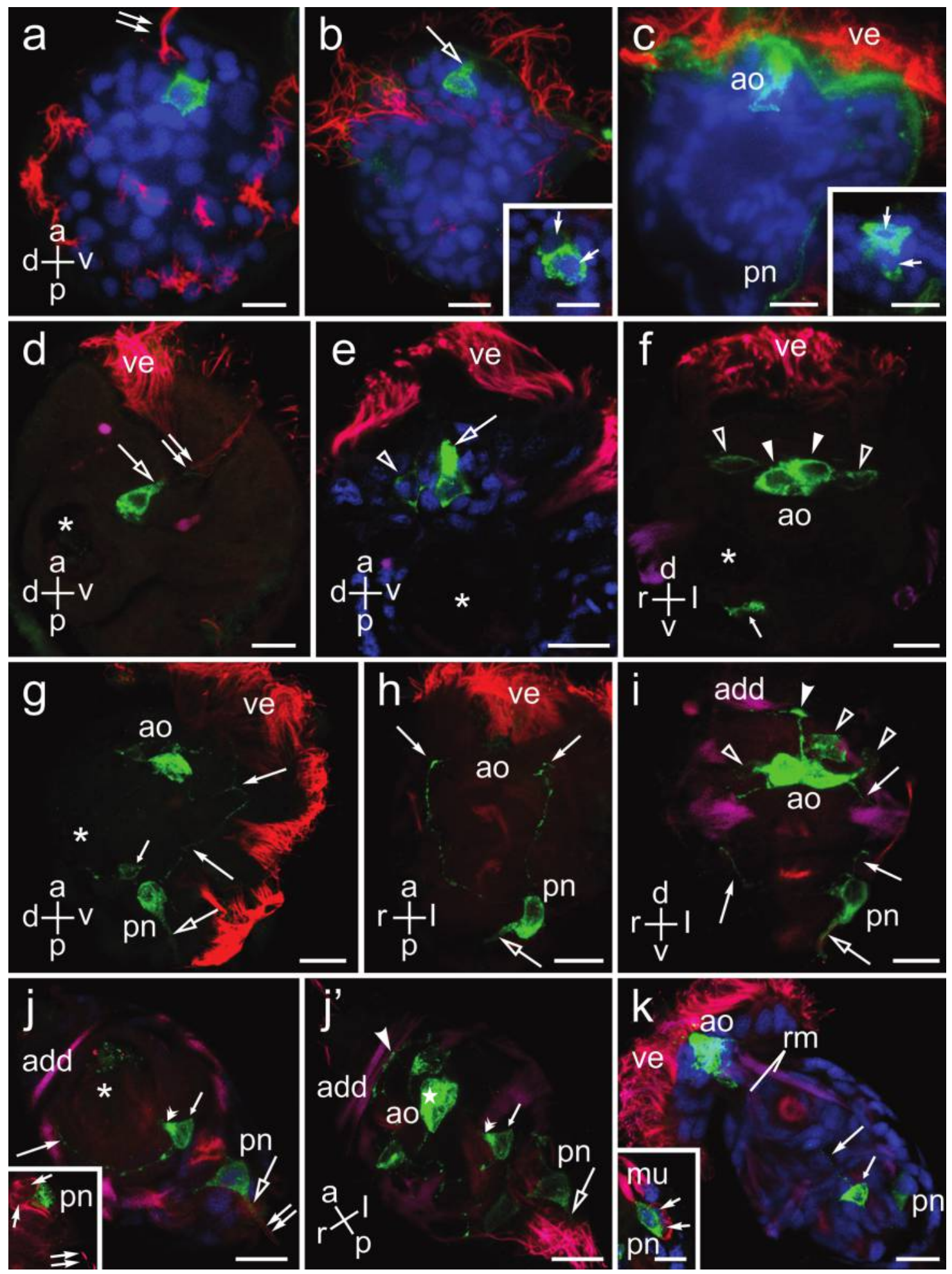

Figure 1. Serotonin-immunoreactive (5-HT-IR, green) neurons in Dreissena polymorpha trochophore and veliger larvae. Red indicates cilia, acetylated tubulin immunoreactivity; magenta indicates muscles, phalloidin staining; blue indicates nuclei, 4',6-diamidino-2-phenylindole (DAPI) staining. Side views show only the left half of the larva, unless otherwise indicated. (a-c) Epifluorescence images. (c-k) Confocal images. (a) Blastula stage (16 hpf). The first 5-HT-IR neuron appears at the anterior extreme, with long cilia (double arrows) seemingly associated with them. (b) Trochophore larva (18 hpf). Labeled flask-shaped cells are located underneath the apical tuft of the cilia. Open arrow indicates short, thick dendrite. (Inset) Top view demonstrating the two 5-HT-IR somata (arrows). (c) Trochophore larva (22 hpf). The two anterior cells with a rudimentary neuropil start to form the apical organ (ao). A single unpaired posterior cell appears at the caudal region. pn, posterior neuron; ve, velum. (Inset) 
was connected directly to the surface, with its sensory dendrite bearing no cilia either. In addition, an FMRFa-IR neuron (the $\mathrm{PN}$ ) at the posterior extreme of the body and four FMRFa-IR cells located laterally and symmetrically (two on the left side and two on the right side) could also be observed. Of the four laterals, two were situated more anteriorly and two more posteriorly. Consequently, they were called right and left lateral anterior cells and right and left posterior cells, respectively. These cells were connected by varicose processes to each other, starting to form a ring and later completing by association with the $\mathrm{AO}$ and the PN.

At $48 \mathrm{hpf}$, a third flask-shaped FMRFa-IR cell appeared in the AO, and a small local neuropil was also detected (Figs. 3c, $\mathrm{d}, 4)$. Three more FMRFa-IR neurons were observed at $48 \mathrm{hpf}$ : one located in the stomach wall, displaying a short dendrite projecting to the stomach lumen, and two cells, one on each side, added to the lateral posterior cells (Figs. 3d, f, 4). This total population of labeled cells remained unchanged until the late veliger stage (96 hpf). Their processes, but not that of the stomach cell, also reached the adductor muscles (Figs. 3e, f, 4).

\section{Pharmacological manipulation of the larval serotonergic system and swimming activity}

To reveal the possible connection between the 5-HT containing early larval neuronal elements and the swimming ac- tivity of Dreissena polymorpha, pharmacological manipulation of the 5-HT synthesis was applied in 48-hpf veligers, combined with quantitative immunofluorescence histochemistry and a swimming assay (Fig. 5).

In control experiments, 48-hpf larvae were found to display upward swimming in the water column. After $30 \mathrm{~min}$, the larvae showed an equal distribution in the upper and lower chambers of the experimental setup (Fig. 5a). Application of $10^{-5} \mathrm{~mol} \mathrm{l}^{-1} \mathrm{pCPA}$, the blocker of tryptophane hydroxylase, significantly decreased the number of larvae reaching the upper chamber (Fig. 5a, b). In contrast, a 1-hour application of $10^{-5}$ mol $1^{-1} 5$-HTP, which is a 5-HT synthesis precursor, significantly enhanced the number of larvae reaching the upper chamber (Fig. 5a, b). Altered fluorescence intensity in the investigated 5-HT-IR sensory elements could be detected by light microscopy (Fig. 5c, d). The relative fluorescence intensity increased by up to $50 \%-75 \%$ after incubation with 5HTP and decreased by about $50 \%$ after pCPA treatment (Fig. 5e-g), showing a positive correlation with the changes detected in swimming activity after the pharmacological interventions.

\section{Effect of increased salinity on the larval 5-HT and FMRFa content and swimming activity}

As a possible environmental effect, we tested the influence of increased salinity on the 5-HT and FMRFa immunoreactiv-

Top view of the 5-HT-IR somata (arrows). (d-f) Apical organ of veliger larvae. Asterisk indicates stomach lumen. ve, velum. (d) Larva (40 hpf). One of the flask-shaped receptor cells with a short, thick dendrite (open arrow) bearing two long cilia (double arrows). (e) Larva (40 hpf). View of the apical organ, with the third neuron (open arrowhead) added at this time to the apical organ. The short, brightly fluorescing structure (open arrow) corresponds to the dendrites of the two early cells appearing at $22 \mathrm{hpf}$. (f) Larva (60 hpf). Two neurons (open arrowheads) appear at this time, lateral to the apical receptor cells (filled arrowheads). Note a single labeled cell (small arrow) located in the stomach wall. (g-i) Lateral (g), ventral (h), and apical (i) view of the posterior neuron of veliger larvae. (g) Larva (40 hpf). The posterior neuron ( $\mathrm{pn}$ ) possesses a thick sensory dendrite (open arrow) running to the caudal surface of the larval body. Its long, thin axon (arrows) runs anteriorly and connects the cell with the apical organ. Small arrow indicates stomach cell; asterisk indicates stomach lumen. (h) Larva ( $40 \mathrm{hpf})$. The labeled perikaryon of the posterior neuron is located on the left side of the larval body. Note thin, long axons (arrows) projecting almost symmetrically to the apical organ along the ventral edges of the larval body. Open arrow indicates sensory dendrite of the posterior neuron. (i) Larva (48 hpf). Thin axons (arrows) connect the posterior neuron with the apical organ, which contains five cells: two centrally located cells with bright fluorescence and one dorsal and two lateral cells with faint fluorescence (open arrowheads). A thick, bright neurite (filled arrowhead) projects from the apical organ to the anterior adductor muscle (add). The open arrow indicates a sensory dendrite of the posterior neuron. $(\mathrm{j}, \mathrm{k})$ Ventral views of veliger (40 hpf, $\mathrm{j}, \mathrm{j}^{\prime}$ ) and late veliger ( $96 \mathrm{hpf}, \mathrm{k}$ ) larvae. ( $\mathrm{j}$ ) The dendrite (open arrow) of the posterior neuron bears two long cilia (double arrows). The labeled cell in the stomach wall (small arrow) projects with a short dendrite (double arrowhead) into the stomach lumen (asterisk) and with a long beaded axon (arrow) anteriorly along the stomach wall. (Inset) Somata of two tubulin-IR cells (arrows) closely adjacent to the posterior neuron. Double arrows indicate cilium of the posterior neuron dendrite. $\left(j^{\prime}\right)$ Whole body view of the larva shown in (j). The thick dendrite (open arrow) of the posterior neuron projects to the body surface, whereas the dendrite (double arrowhead) of the stomach cell (small arrow) projects to the stomach lumen. Asterisk indicates the neuropil of the apical organ; arrowhead indicates a neurite projecting from the apical organ to the anterior adductor muscle. (k) Two retractor muscle (rm) bundles associated with the apical organ. Posterior and stomach (small arrow) neurons are also visible. Arrows indicate thin axon projecting from the stomach cell toward the apical organ. (Inset) Higher view of the somata of two tubulin-immunopositive cells (arrows) near the posterior neuron and adjacent muscles (mu). add, anterior adductor muscle; ao, apical organ; hpf, hours post-fertilization; mu, muscle; pn, posterior neuron; rm, retractor muscle; ve, velum. Scale bars $=10 \mu \mathrm{m}$. The crossbars located in the corners of a, $\mathrm{d}-\mathrm{i}$, and $\mathrm{j}^{\prime}$ indicate anterior (a), posterior (p), dorsal (d), ventral (v), left (l), and right (r). 

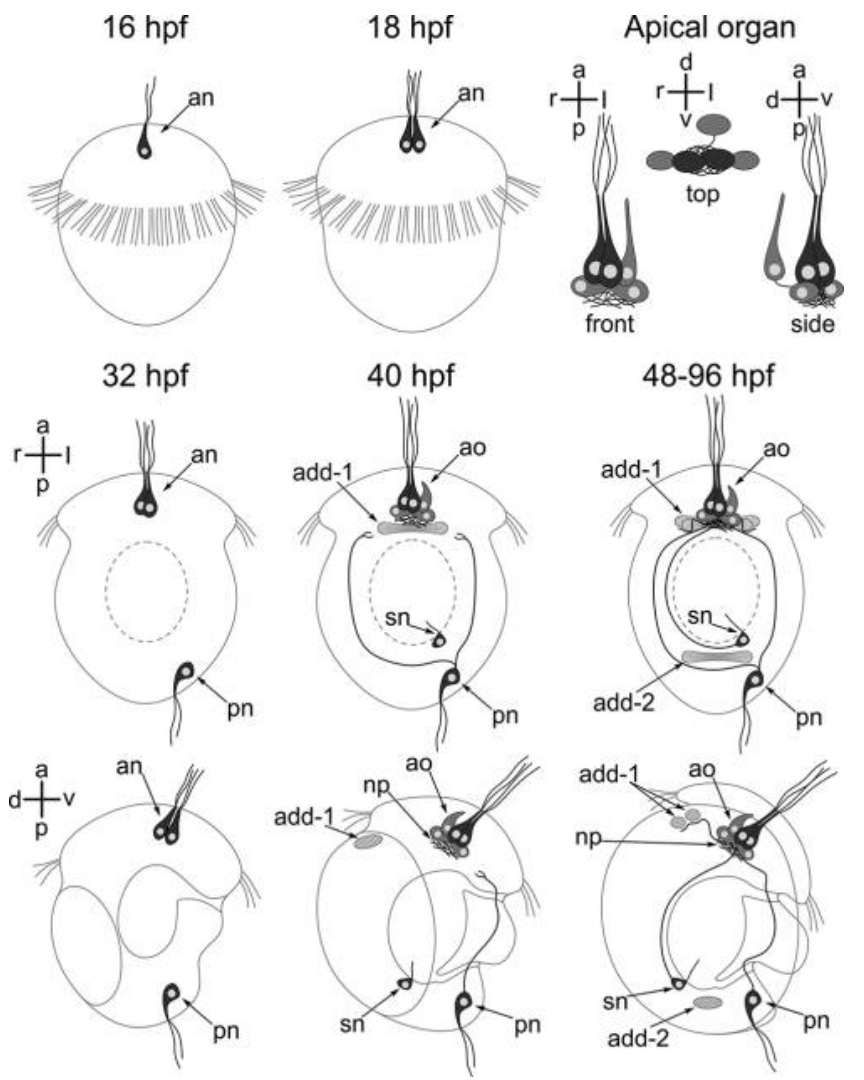

Figure 2. Schematic drawing showing the development and distribution of serotonin-immunoreactive (5-HT-IR) neurons and their neurites in trochophore (16-32 hours post-fertilization [hpf]) and veliger (40-96 hpf) larval stages of Dreissena polymorpha. The apical pole is always shown upward. Upper and middle rows are ventral views; the lower row is a right-side view. Detailed organization of the apical organ at $48-96 \mathrm{hpf}$ is shown in the right upper panel. add-1, anterior adductor muscle; add-2, posterior adductor muscle; an, apical neuron; ao, apical organ; np, neuropil; pn, posterior neuron; sn, stomach neuron. The crossbars indicate anterior (a), posterior (p), dorsal (d), ventral (v), left (l), and right (r).

ity of identified neuronal structures (Figs. 6,7) and the swimming activity (Fig. 5a, b) of 48-hpf Dreissena larvae. After $24 \mathrm{~h}$ of incubation in FW containing $2 \mathrm{~g} \mathrm{l}^{-1}(2 \%) \mathrm{NaCl}$, the swimming activity of the larvae increased significantly (Fig. 5a, b). Also, fluorescence intensity was changed in all selected 5-HT-IR (Fig. 6a) and FMRFa-IR (Fig. 7a) neurons, compared to the control. In the case of 5-HT-IR cells, this elevated fluorescence intensity could clearly be seen in the sensory and interneurons of both the AO and the PN (Fig. 6b). It was also supported by the quantification of the relative brightness of immunolabeling (Fig. 6c). The most sensitive element reacting to increased salinity was the $\mathrm{PN}$, showing a $150 \%$ increase in fluorescence intensity compared to the control, followed by the apical intrinsic neurons, with about a $100 \%$ increase. Meanwhile, the apical sensory neurons and the neuropil region of the $\mathrm{AO}$ showed less than a $50 \%$ increase
(Fig. 6c). In the case of FMRFa-IR larval neuronal elements, the response to increased salinity was different (Fig. 7b, c). The AO and lateral cells showed a significant increase of brightness intensity, compared to the control (Fig. 7c'), whereas FMRFa-IR fluorescence intensity in other neuronal structures, such as the AO neuropil and the PN, remained near the control value.

\section{Discussion}

The present study was devoted to the early (trochophore and veliger) neurodevelopmental events of an invasive bivalve species, the zebra mussel, Dreissena polymorpha, with special attention to 5-HT- and FMRFamide-containing cells, respectively, two pivotal signal molecules playing various roles in the regulatory processes of molluscs. Our findings provide, on the one hand, a detailed, until now unknown description of the larval neuronal development of Dreissena 5HTergic and FMRFaergic sensory systems and, on the other, data on the possible involvement of these sensory systems in the swimming activity (possibly related to settlement competency) of this bivalve. The analysis of the effect of the pharmacological manipulation of the 5-HTergic system and enhanced salinity on the swimming behavior of the larvae, combined with quantitative IHC, points to a correlation between the appearance of a set of early sensory elements, their transmitter content, and the swimming activity of the bivalve larvae. This suggests that the role of these neurons in elaborating early strategies is possibly involved in the successful distribution of Dreissena, at the expense of other aquatic organisms. Studies on the neuronal development of different invertebrate Trochozoa species have shown that they possess a well-developed nervous system, which certainly detects and processes environmental stimuli (Lacalli, 1984; Hay-Schmidt, 1995; Kempf et al., 1997; Page, 2002; Voronezhskaya et al., 2004). According to earlier and recent data, the larval nervous system of bivalves already possesses, as in gastropods, an early transient sensory system, which is mainly concentrated in the AO (Ospovat et al., 1989; Koolakovsky and Phlyachinskaya, 1993; Croll et al., 1997; Kreiling et al., 2001; Voronezhskaya et al., 2008; He et al., 2015).

\section{Organization and morphological characteristics of the early larval nervous system in Dreissena}

According to our IHC findings, in both the 5-HT-IR and FMRFa-IR systems visualized in larval Dreissena, three sensory "centers" appear during the 96-hour-long trochophore and veliger stages. The three different locations (apical, posterior, and stomach) of sensory cells remain the anatomical backbone of the larval organization of the Dreissena sensory system until the end of the veliger stage (96 hpf). Although 

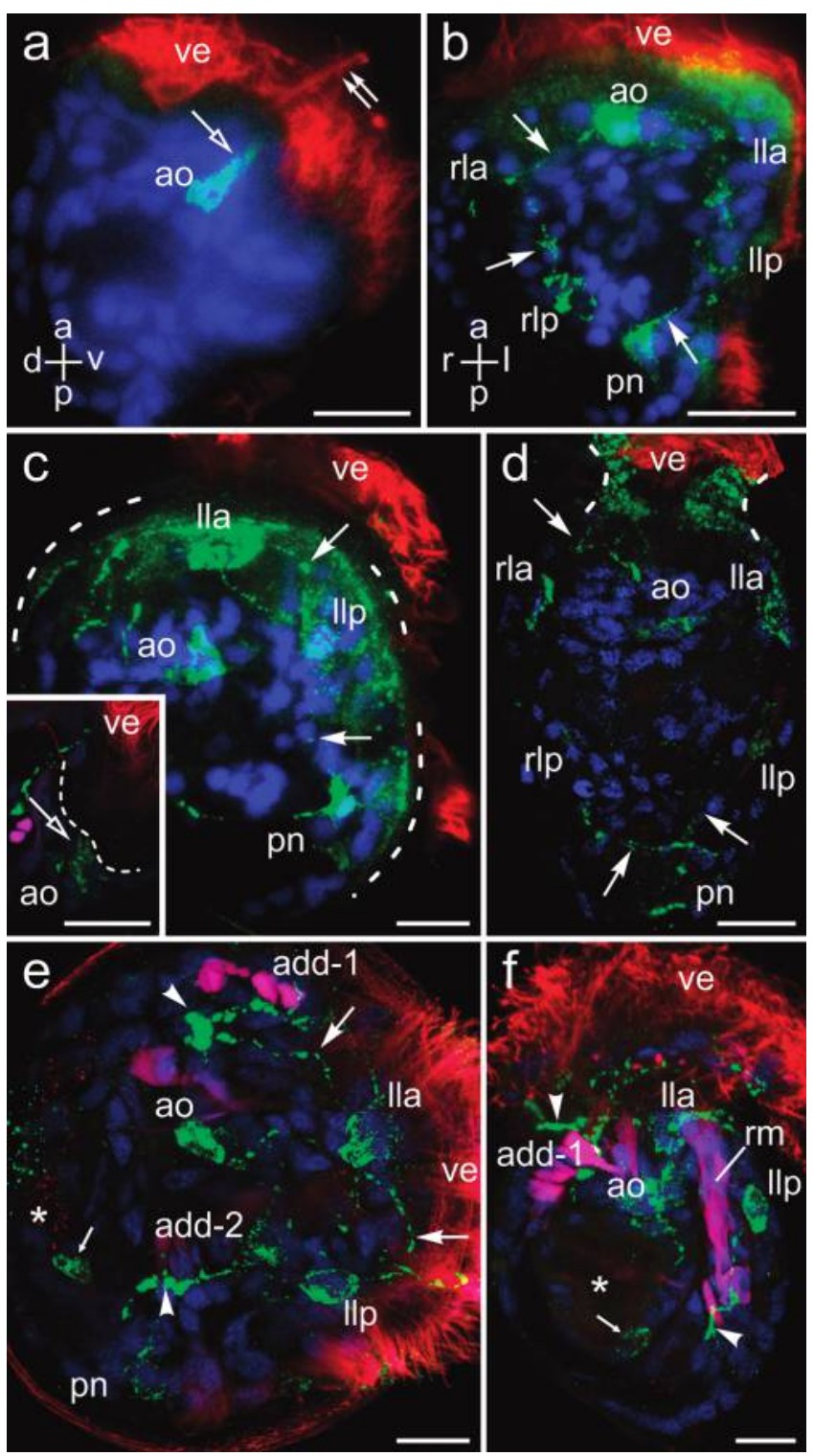

Figure 3. FMRFamide-immunoreactive (FMRFa-IR, green) neurons in trochophore and veliger Dreissena polymorpha larvae. Red indicates cilia, acetylated tubulin immunoreactivity; magenta indicates muscles, phalloidin staining; blue indicates nuclei, 4',6-diamidino-2-phenylindole (DAPI) staining. Left column (a, c, e) represents left-side views; right column (b, d, f) represents ventral views. (a-d) Epifluorescence images. (e, f) Confocal images. (a) Trochophore larva (32 hpf). A single flask-shaped cell located at the anterior extreme underneath the apical tuft of cilia (double arrows), projecting to the surface with its short, thick sensory dendrite (open arrow). (b) Early veliger larva (40 hpf). The apical organ containing two cells, a brightly and a faintly fluorescing one. A single unpaired neuron is located posteriorly on the left side of the larval body, and four cells are seen laterally, two on the left side (1lp, lla) and two on the right side (rlp, rla). Arrows indicate thin varicose processes originating from the posterior neuron and the lateral cells, respectively. (c, d) Veliger larva (48 hpf) with the apical organ, the posterior cell, and the lateral neurons (1lp, lla, rlp, rla) along the mantle edge (dashed line). All cells are connected by thin varicose processes (arrows). (Inset in c) Three apical organ receptor cell dendrites (open arrow) projecting to the body surface (thin dashed line). (e, f) Larva ( $96 \mathrm{hpf}$ ). The apical organ and the posterior and lateral neurons (1lp, 1la) are connected by varicose neurites the basic pattern of organization and development of both signaling systems is similar, significant differences in the timing of appearance and details of their neuromorphology could also be observed. As to the similarities, the flask-form 5-HT-IR and FMRFa-IR sensory cells appear first in the apical region, gradually forming the $\mathrm{AO}$, which is followed by the emergence of the PN and stomach sensory neurons. The sensory neurons displayed typical bipolar morphology, with a robust sensory dendrite and a thin sensory axon, the latter sometimes bifurcating. The visualization of PN and stomach cells is an a priori observation that we believe has not been described before in molluscan trochophore and veliger larvae. A posterior sensory organ in a trochophore larva was identified earlier in a polychaete, Phyllodoce maculate (Nezlin and Voronezhskaya, 2003). The organ consisted of five bipolar sensory cells displaying similar morphology to the PN found in Dreissena, of which two were also 5-HTimmunopositive.

The differences between the 5-HT-IR and FMRFa-IR systems are as follows. (i) Nonsensory 5-HT-IR cells are added to the $\mathrm{AO}$ by the beginning of the veliger stage (not observed in the case of the FMRFa-IR AO). (ii) The tips of the sensory dendrite 5-HT-IR AO and the 5-HT-IR posterior neurons are supplied with cilia, whereas the FMRFa-IR sensory dendrites do not bear cilia. Although they possess no cilia, the role of FMRFa-IR sensory dendrites in perceiving environmental information is assumed (see Fig. 7). In the case of 5-HT-IR sensory neurons, the receptor molecules are most probably located on the cilia, whereas in FMRFa-IR elements they can be bound to the dendritic membrane. (iii) The 5-HT-IR sensory elements appear at an early thochophore stage (16 hpf), whereas the first FMRFa-IR cells can be observed only by the late trochophore and early veliger stages (32-40 hpf), followed at $40 \mathrm{hpf}$ by another cell added to the AO, as well as by the posterior FMRFa-IR neuron and the first anterior and posterior lateral cells. In the early veliger stage, the complete 5-HT-IR system (totaling seven cells) is already present with most of its processes. However, from $48 \mathrm{hpf}$, both signaling systems are completely developed, which then can be observed until the end of the studied veliger stage (96 hpf). From the early (48 hpf) veliger stage, the 5-HT-IR nervous system contains altogether seven neurons: five in the AO, as well as the single PN and the stomach cell. At the same time, the 11 FMRFa-IR neurons are distributed as follows: 3 comprise the AO, and 6 are located laterally, in addition to the single PN and the stomach cell.

(arrows). Note FMRFa-IR processes (arrowheads) originating from the lateral neurons, which run to or near the anterior and posterior adductor and the retractor muscles (f). Small arrow indicates labeled stomach cell; asterisk indicates stomach lumen. Scale bars $=10 \mu \mathrm{m}$. add-1, anterior adductor muscle; add-2, posterior adductor muscle; ao, apical organ; hpf, hours postfertilization; pn, posterior neuron; rm, retractor muscle; ve, velum. The crossbars located in the corners of a and b indicate anterior (a), posterior ( $\mathrm{p}$ ), dorsal (d), ventral (v), left (1), and right (r). 

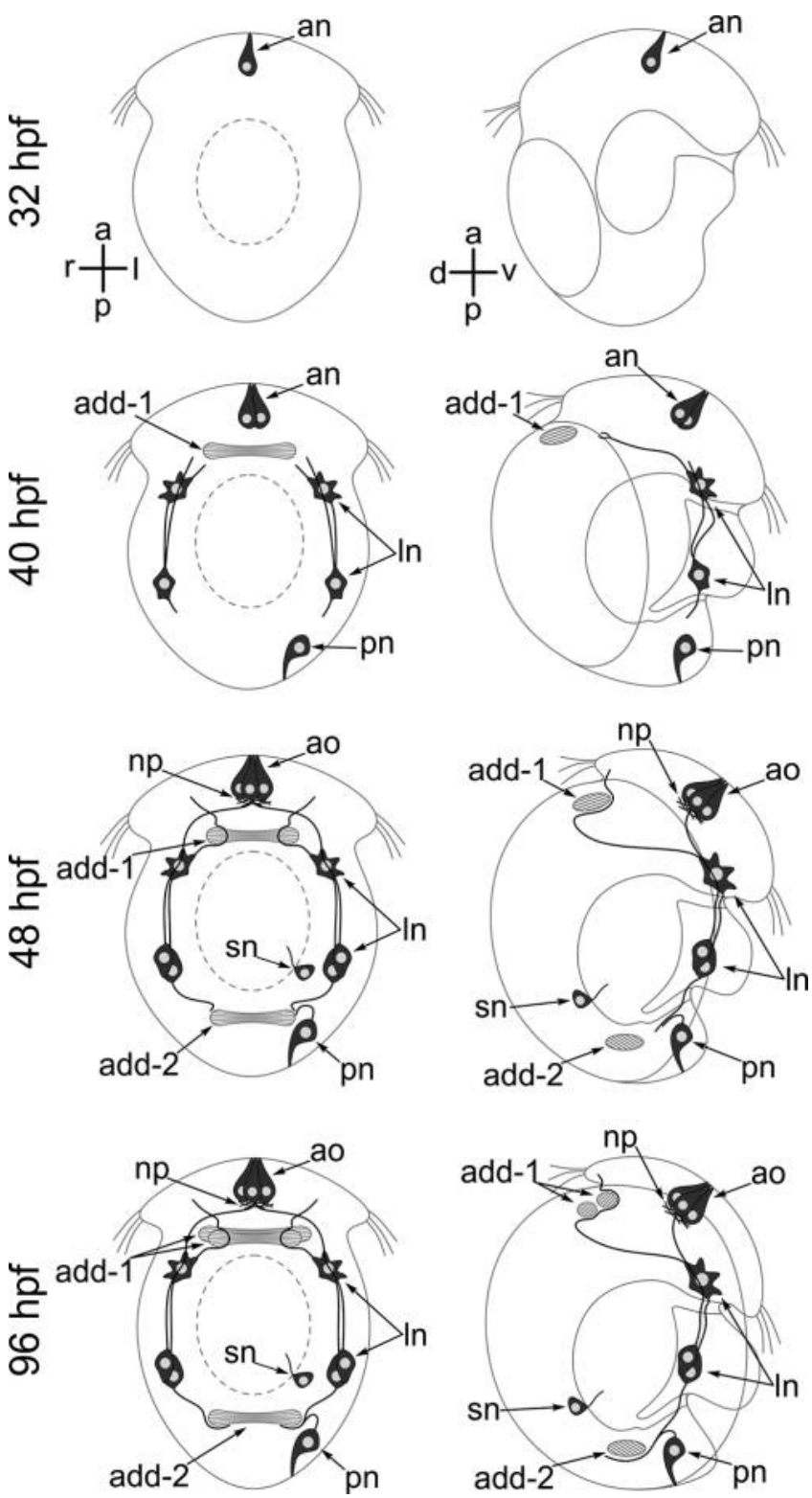

Figure 4. Schematic drawing showing the development and distribution of FMRFamide-immunoreactive (FMRFa-IR) neurons and their neurites in trochophore (32-40 hours post-fertilization [hpf]) and veliger (48-96 hpf) larval stages of Dreissena polymorpha. The apical pole is always shown upward. The left column represents ventral views, and the right column represents right-side views. add-1, anterior adductor muscle; add-2, posterior adductor muscle; an, apical neuron; ao, apical organ; ln, lateral neuron; np, neuropil; pn, posterior neuron; sn, stomach neuron. The crossbars indicate anterior (a), posterior (p), dorsal (d), ventral (v), left (l), and right (r).

A very similar early 5-HTergic system has been described in bivalve trochozoa larva of Mytilus trossulus (Voronezhskaya et al., 2008), in which the first 5-HT-IR neuron appeared in the apical region of the trochophore, followed soon thereafter by four others, thus increasing the number of this type of cells to five. In contrast to Dreissena, however, the 5-HT-IR neurons were restricted to the apical region throughout the entire larval development. The larval organization of the 5-HTergic system is remarkably similar, even in phylogenetically distant gastropod species (Barlow and Truman, 1992; Kempf et al., 1997).

Other transmitters have also been shown in sensory neurons of developing molluscs. FMRFa-IR sensory cells were found in the $\mathrm{AO}$ of the trochophore larvae of the marine bivalve Mytilus (Voronezhskaya et al., 2008), as well as in the AO of developing aplachophoran molluscan species (Redl et al., 2014). Tyrosine-hydroxylase-IR (dopamine-containing) sensory neurons appeared first in the AO and the foot of the trochophore larvae of the pond snail Lymnaea stagnalis and later in the tentacle and the lips during the veliger stage (Voronezhskaya et al., 1999). Also in Lymnaea, nitrogen monoxidecontaining peripheral sensory neurons were found in the foot, mantle edge, and lips during the postmetamorphic period of embryogenesis (Serföző et al., 1998).

Another important anatomical aspect, possibly from a functional point of view, is that while the apical cells do not send axons descending to the PN and/or the stomach neurons, the latter two in 5-HT immunolabeling and in the FMRFa-IR PN project to the AO, suggesting that they forward sensory information about the caudal (environmental) region and the feeding (satiation) state of the veliger to the AO. Therefore, in addition to its own sensory function, an integrative role of $\mathrm{AO}$ is also assumed, supported by the presence of a neuropil-like structure.

The AO, which is a pivotal sensory structure in freeswimming larvae also involved in the control of the velar prototrochal cilia function (Kempf et al., 1997), shows basic organization similarities in different planktonic and freeliving gastropod species. In the course of ultrastructural investigations on Aplysia californica veligers, Marois and Carew (1997) have demonstrated five 5-HT-IR cells (one-third of all AO cells), among which three ampullary (sensory) neurons and two interneurons were found. In the AO of planktotrophic caenogastropod larvae, three to six, but in most cases five, 5-HT-IR sensory (ampullary and para-ampullary) cells and two lateral nonsensory cells were described (Page and Parries, 2000). Similarly, five 5-HT-IR cells, among them three sensory (ampullary) neurons and two interneurons, as well as a neuropil with extensions to the developing cerebral ganglia, were found in the AO of nudibranch larvae (Kempf et al., 1997). The organization of the Dreissena AO fits well in this general form of cellular arrangement described in other molluscs; hence, it is suggested that the additional presence of interneurons and a neuropil in the $\mathrm{AO}$ is a consequent feature and can be regarded as morphological evidence of local integrative processes.

An intriguing question concerns the appearance of the FMRFa-IR lateral cells, missing from the larval 5-HTergic system. According to our observations (see Fig. 4), the labeled cells are connected by long processes to the AO. In addition, they project to the adductor muscles, raising the pos- 
a

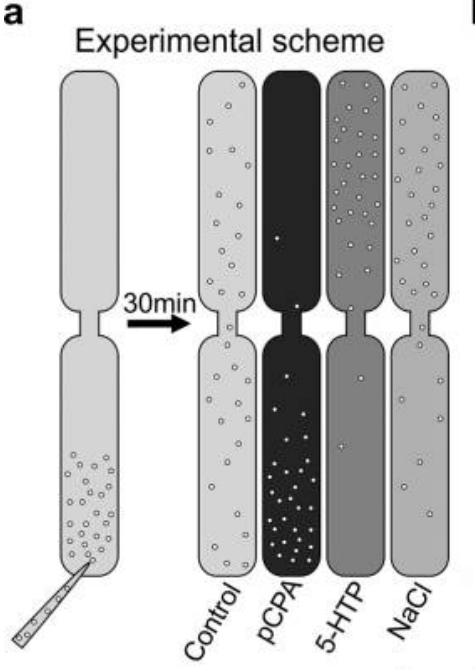

b

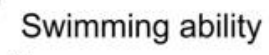

$\%$

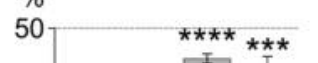

c

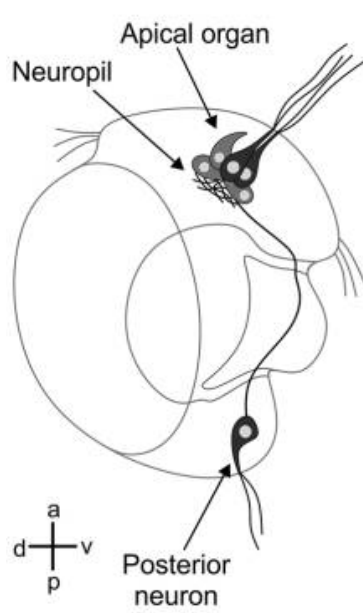

d Apical organ

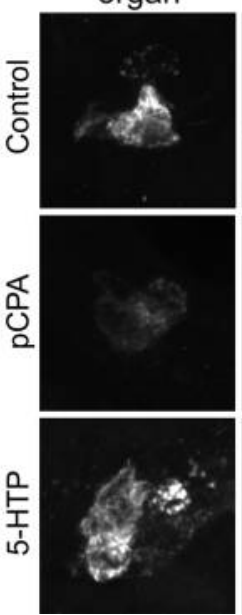

e
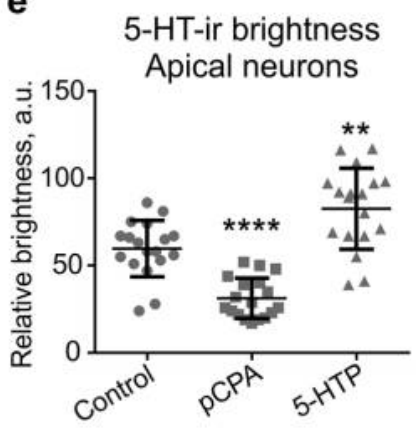

f
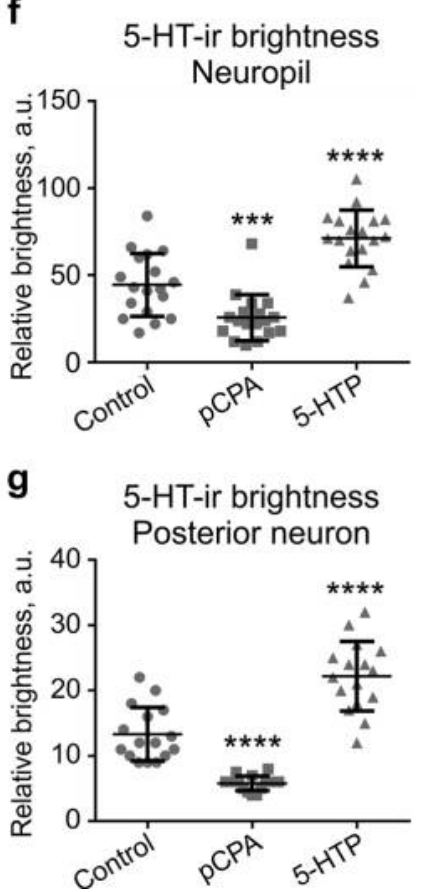

Figure 5. Swimming activity of Dreissena polymorpha veliger larvae (48 hours post-fertilization [hpf]) and changes in relative fluorescence intensity of serotonin-immunoreactive (5-HT-IR) neurons, following the pharmacological manipulation of 5-HT synthesis. (a) Experimental scheme of the larval swimming assay. Following incubation in testing solutions, the larvae were transferred into the lower tube of the testing set. After 30 minutes the animals from the upper and lower tubes of the testing set were collected and counted. (b) Quantitative evaluation of swimming assay. Light gray indicates percent of actively swimming larvae in the upper tube; dark gray indicates larvae in the lower tube. Incubation with para-chlorophenilalanine (pCPA) $\left(10^{-5} \mathrm{~mol} \mathrm{l}^{-1}, 6\right.$ hours) resulted in a significant decrease of larval swimming activity; application of 5-hydroxytryptophan (5-HTP) $\left(10^{-5} \mathrm{~mol} \mathrm{1}^{-1}\right.$, 1 hour) significantly enhanced swimming activity. Incubation of the larvae in $2 \%$ NaCl also evoked increased swimming activity. (c) Schematic representation of the relative fluorescence intensity of 5-HT-IR neuronal elements. (d) Representative micrographs demonstrating the changes of immunofluorescence intensity of 5-HT-IR neurons of control, pCPA-treated, and 5-HTP-treated larvae. (e-g) Quantitative evaluation of relative brightness after drug administration in the apical neurons, neuropil, and posterior neuron, respectively. Immunoreactivity in all examined units decreased after pCPA treatment and increased after 5-HTP treatment. Each point represents a single measurement. Data are given as mean \pm SEM. Two asterisks, $P<0.005$; three asterisks, $P<0.0001$; four asterisks, $P<0.0001$, according to a Mann-Whitney $U$ test. The crossbar in (c) indicates anterior (a), posterior (p), dorsal (d), and ventral (v). a.u., arbitrary units.

sibility either of their direct regulatory role in early muscle function or of their involvement in the development of the muscle, thus acting as trophic factors. In chiton larvae, transient dorsolateral cells, although sensory, showing FMRFa immunoreactivity have been described previously (Haszprunar et al., 2002; Voronezhskaya et al., 2002).

The long axon processes of both the lateral cells and the sensory neurons appear to bear varicosities along their entire 
a

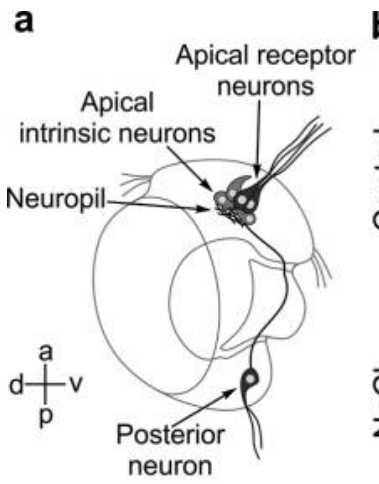

C

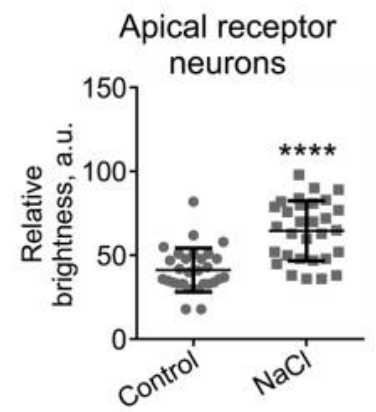

Neuropil

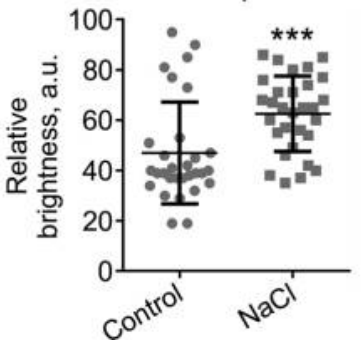

b Apical organ
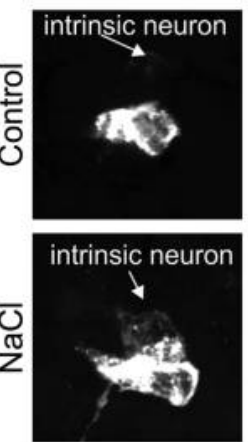

Posterior neuron
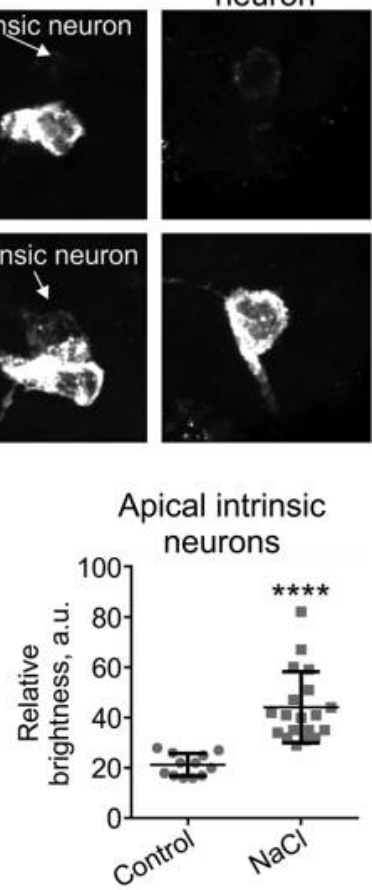

Posterior neuron

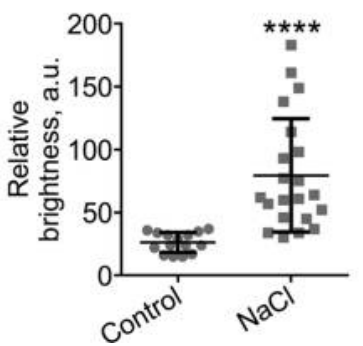

Figure 6. Serotonin-immunoreactive (5-HT-IR) neuronal elements in Dreissena polymorpha veligers (48 hours post-fertilization [hpf]) after incubation in $2 \% 0 \mathrm{NaCl}$ for 24 hours. (a) Schematic representation of the relative fluorescence intensity of 5-HT-IR neuronal elements. (b) Representative micrographs of 5-HT-IR neurons of control and experimental larvae, demonstrating enhanced immunofluorescence intensity on the effect of increased salinity. (c) Quantification of relative brightness in the apical neurons, neuropil, and posterior neuron. All tested 5-HT-IR neuronal structures responded to increased salinity by significantly enhanced 5-HT-IR brightness. The maximum change was detected in the posterior neuron. Each point represents a single measurement. Data given as mean \pm SEM. Three asterisks, $P<0.0001$; four asterisks, $P<$ 0.0001 , according to a Mann-Whitney $U$ test. The crossbar in (a) indicates anterior (a), posterior (p), dorsal (d), and ventral (v). a.u., arbitrary units.

length until reaching their targets, the $\mathrm{AO}$ or the adductor muscles. The presence of varicosities may refer to the free release of 5-HT or FMRFa at varicosities, in this way exerting remote control (fine tuning) of (i) early physiological and/or behavioral events, such as velum cilia movement and related swimming activity, and (ii) the development and/or regulation of somatic events of the veliger Dreissena larvae. Both 5-HT and FMRFamide have been shown to be involved in remote control actions in a number of invertebrates, including

molluscs, by varicose fibers located in the connective tissue covering the ganglia and/or peripheral nerves, as well as situated directly on their surface (see, e.g., Nässel, 1988, 1996; Elekes and Nässel, 1990; Elekes, 1991; Beltz, 1995). In Lymnaea embryos of the E40 stage, pharmacological manipulation of the 5-HTergic system by 5-HT agonists resulted in a significant rotational increase (Filla et al., 2009), whereas in early (E25) trochophore embryos of Helisoma trivolvis, a pair
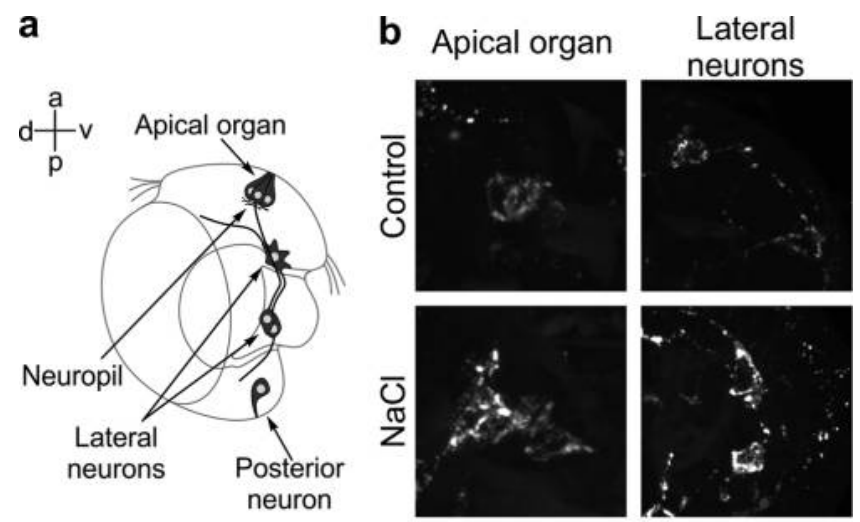

C
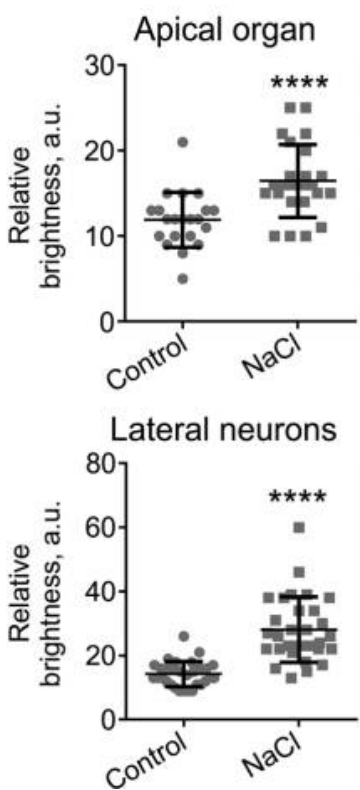



Posterior neuron

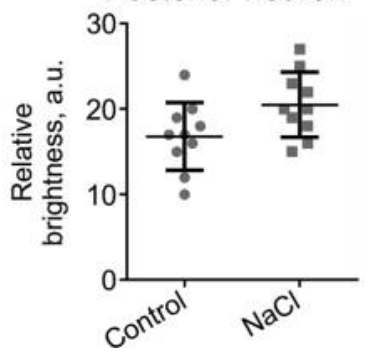

Figure 7. FMRFamide-immunoreactive (FMRFa-IR) neuronal elements in Dreissena polymorpha veligers (48 hours post-fertilization [hpf]) after incubation in $2 \% 0 \mathrm{NaCl}$ for 24 hours. (a) Schematic representation of the relative fluorescence intensity of FMRFa-IR neuronal elements. (b) Representative micrographs of FMRFa-IR neurons of control and experimental larvae, demonstrating the effect of increased salinity on the immunofluorescence intensity. (c) Quantification of relative FMRFa-IR intensity. FMRFa-IR brightness was significantly changed in the apical organ (AO) neurons and the lateral cells, whereas brightness within the AO neuropil and the posterior neuron was similar to that of the control. Each point represents a single measurement. Data are given as mean \pm SEM. Four asterisks, $P<0$. 0001, according to a Mann-Whitney $U$ test. The crossbar in (a) indicates anterior (a), posterior (p), dorsal (d), and ventral (v). a.u., arbitrary units. 
of identified 5-HTergic neurons, the future giant 5-HTegic cells in adults, were shown to send neurites to surface ciliary cells responsible for rotation (see, e.g., Diefenbach et al., 1991; Kuang and Goldberg, 2001; Koss et al., 2003).

\section{Functional-physiological considerations}

In the present study we have made an attempt to deliver pharmacological, physiological, and quantitative immunoflourescence data for the possible involvement of 5-HTergic and FMRFaergic signaling systems in the regulation of the locomotion (swimming) behavior of larval Dreissena. Changes of 5-HT immunoreactivity in the sensory neurons and interneurons evoked by either stimulating or blocking the 5-HT synthesis were accompanied by the alteration of swimming behavior. This raises the question of the role of this monoamine in the regulation of Dreissena larvae swimming. Serotonin has long been demonstrated to play a role in a series of central and peripheral modulatory processes of gastropods (see, e.g., Walker, 1986; Walker et al., 1996; Gillette, 2006), including embryonic development and different behaviors, such as feeding and locomotion (rotation and gliding) (Helisoma trivolvis, Goldberg et al., 1994; Doran et al., 2004; Lymnaea stagnalis, Filla et al., 2009; Balog et al., 2012; IB, KE, RH, EEV, G. Balog, L. Hiripi, M. Y. Khaborova, G. Maász, unpubl. obs.). In Lymnaea veliger larvae, no 5-HT immunolabeling could be detected following pCPA treatment, and pharmacological treatments affecting the 5-HTergic system (including specific receptors) influenced both early larval rotation and post-metamorphotic gliding, as well as the 5-HT-IR innervation of the buccal mass and related radula protrusion. In Helisoma embryos, the innervation of ciliary cells by an identified pair of 5-HTergic neurons (Koss et al., 2013) and the role of 5-HTergic receptors in ciliary beating, as well as the direct effect of 5-HT on the Ca content of ciliary cells, have been described (Doran et al., 2004). In an early study by Koshtoyants et al. (1961), the exogenous application of 5-HT was shown to accelerate ciliary beating in larval gastropods.

The perception and correct interpretation of inputs, including chemical stimuli, from the surrounding world are pivotal throughout the entire life period in the animal kingdom. They are equally important in sustainment (feeding, predation, escape) and reproduction. However, during early development they may also have a role in initiating events related to the finalization of somatic and regulatory processes. In this respect, free-living aquatic larvae are especially vulnerable when searching for the optimal settlement sites. Therefore, our experiments with increased salinity can be regarded as an approach in analyzing the possible effect of the change of environment on the sensory-motor system of the invasive Dreissena. According to our findings, both the 5-HT-IR and FMRFa-IR sets of neurons of the larval Dreissena nervous (sensory) system respond to increased salinity through a significantly higher inten- sity of immunofluorescence, compared to the control cells. This suggests the involvement of the anterior and caudal sensory centers in the perception of changes in the environment, in this case, higher salinity. The fact that the apical interneurons, the AO neuropil, and the lateral cells also reacted may indicate the participation of nonsensory, integratory elements in processing the salinity effect. In the case of the PN and the lateral cells, an efferent transmission toward the developing adductor muscles is also assumed. In the larvae of freshwater snails Lymnaea and Helisoma, early FMRFa-IR neurons were shown to be involved in osmoregulation, and an elevated FMRFa level had a stimulating effect on 5-HT synthesis (Chaban and Voronezhskaya, 2008). Although increased salinity was found in our study to initiate a high intensity of swimming activity of the Dreissena veligers, recently it was also shown to be a limiting factor for the dispersal of both dreissenid and mytilid bivalves (van der Gaag et al., 2016). The marine bivalve Crenomytilus grayanus proved to be very sensitive to changes in salinity, which could block feeding and retard larval growth (Yaroslavtseva and Sergeeva, 2010). Moreover, it was shown that changes in salinity have an impact on the growth and survival of the larvae of another marine bivalve, Mytilus trossulus, influencing simultaneously the expression of 5-HT and FMRFa immunoreactivities (Vekhova et al., 2012). In the marine snail Ilyanassa obsoleta, acidic seawater was found to stimulate metamorphosis, a process also regulated by different transmitter systems, such as 5-HT, nitric oxide, and FMRFamide (Leise and Cahoon, 2012; Leise et al., 2014). When applying conditioned water to study conspecific adult-to-embryo information transmission, the role of 5-HTergic and dopaminergic $\mathrm{AO}$ neurons in retarding embryogenesis and related behaviors, such as rotation, was demonstrated in Helisoma and Lymnaea (Voronezhskaya et al., 2004).

The changes in the 5-HTergic and FMRFamidergic neuronal systems, accompanied by the altered swimming behavior of the Dreissena veligers observed in our study, both in the effect of pharmacological interventions and in increased salinity, may help, on the one hand, to better understand the development of the larval bivalve (molluscan) nervous system and, on the other, shed light on the possible neuronal background of behavioral responses to environmental factors. We assume that early detection of an environmental input-be it attractive or repellent - may decisively influence the proper preparation of the bivalve to select an optimal site for settlement.

\section{Acknowledgments}

This work was supported by grants from the Hungarian Scientific Research Fund (OTKA) to KE (K111990) and from the Russian Foundation for Basic Research to LPN (14-04-00673) and Russian Science Foundation to EEV (17-14-01353). The skilful technical assistance of Mrs. Zsuzsanna N. Fekete and Mr. Boldizsár Balázs is greatly appreciated. 


\section{Literature Cited}

Ackerman, J. D., B. Sim, S. J. Nichols, and R. Claudi. 1994. A review of the early life history of zebra mussels (Dreissena polymorpha): comparisons with marine bivalves. Can. J. Zool. 72: 1169-1179.

Aldridge, D. C., M. Salazar, A. Serna, and J. Cock. 2008. Densitydependent effects of a new invasive false mussel, Mytilopsis trautwineana (Tryon 1866), on shrimp, Litopenaeus vannamei (Boone 1931), aquaculture in Colombia. Aquaculture 281: 34-42.

Aranda-Burgos, J. A., F. Da Costa, S. Nóvoa, J. Ojea, and D. MartínezPatino. 2014. Embryonic and larval development of Ruditapes decussatus (Bivalvia: Veneridae): a study of the shell differentiation process. J. Molluscan Stud. 80: 8-16.

Balog, G., E. E. Voronezhskaya, L. Hiripi, and K. Elekes. 2012. Organization of the serotonergic innervation of the feeding (buccal) musculature during the maturation of the pond snail Lymnaea stagnalis: a morphological, biochemical and physiological study. J. Comp. Neurol. 520: 315-329.

Barlow, L. A., and J. W. Truman. 1992. Patterns of serotonin and SCP immunoreactivity during metamorphosis of the nervous system of the red abalone, Haliotus rufescens. J. Neurobiol. 26: 829-844.

Beklemishev, W. N. 1969. Principles of Comparative Anatomy of Invertebrates: Organology. University of Chicago Press, Chicago.

Beltz, B. 1995. Neurobiology and neuroendocrinology. Pp. 267-289 in Biology of the Lobster Homarus americanus, J. B. Factor, ed. Academic Press, New York.

Bobeldyk, A. M., J. M. Bossenbroek, M. A. Evan-White, D. M. Lodge, and G. A. Lamberti. 2005. Secondary spread of zebra mussels (Dreissena polymorpha) in lake-stream systems. Ecoscience 12: 414-421.

Buznikov, G. A. 2007. Preneural transmitters as regulators of embryogenesis: current state of the problem. Russ. J. Dev. Biol. 38: 213-220.

Chaban, A. K., and E. E. Voronezhskaya. 2008. Involvement of transient larval neurons in osmoregulation and neurogenesis in the freshwater snails, Lymnaea stagnalis and Helisoma trivolis. Acta Biol. Hung. 59(suppl.): 123-126.

Claudi, R., and M. L. Gerald. 1994. Practical Manual for Zebra Mussel Monitoring and Control. CRC, Boca Raton, FL.

Croll, R. P. 2000. Insights into early molluscan neuronal development through studies of transmitter phenotypes in embryonic pond snails. Microsc. Res. Tech. 49: 570-578.

Croll, R. P. 2006. Development of embryonic and larval cells containing serotonin, catecholamines, and FMRFamide-related peptides in the gastropod mollusc Phestilla sibogae. Biol. Bull. 211: 232-247.

Croll, R. P., and A. J. G. Dickinson. 2004. Form and function of the larval nervous system in molluscs. Invertebr. Reprod. Dev. 46: 173187.

Croll, R. P., and E. E. Voronezhskaya. 1995. Early FMRFamide-like immunoreactive cells in gastropod neurogenesis. Acta Biol. Hung. 46: 295-303.

Croll, R. P., and E. E. Voronezhskaya. 1996. Early elements in gastropod neurogenesis. Dev. Biol. 173: 344-347.

Croll, R. P., D. L. Jackson, and E. E. Voronezhskaya. 1997. Catecholamine-containing cells in larval and postlarval bivalve molluscs. Biol. Bull. 193: 116-124.

Da Costa, F., S. Darriba, and D. Martínez-Patino. 2008. Embryonic and larval development of Ensis arccuatus (Jefferys, 1865) (Bivalvia: Pharidae). J. Molluscan Stud. 74: 103-109.

Dickinson, A. J., R. P. Croll, and E. E. Voronezhskaya. 2000. Development of embryonic cells containing serotonin, catecholamines and FMRFamide-related peptides in Aplysia californica. Biol. Bull. 199: 305-315.

Diefenbach, T. J., N. K. Koehncke, and J. I. Goldberg. 1991. Characterization and development of rotational behavior in Helisoma embryos: role of endogenous serotonin. J. Neurobiol. 22: 922-934.
Diefenbach, T. J., R. Koos, and J. I. Goldberg. 1998. Early development of an identified serotonergic neuron in Helisoma trivolvis embryos: serotonin expression, de-expression and uptake. J. Neurobiol. 34: 361376.

Doran, S. A., R. Koss, C. H. Tran, K. J. Christopher, W. J. Gallin, and J. I. Goldberg. 2004. Effect of serotonin on ciliary beating and intracellular calcium concentration in identified populations of embryonic ciliary cells. J. Exp. Biol. 207: 1415-1429.

Dyachuk, V. A., and N. A. Odintsova. 2009. Development of the larval muscle system in the mussel Mytilus trossulus (Mollusca, Bivalvia). Dev. Growth Differ. 51: 69-79.

Elekes, K. 1991. Serotonin-immunoreactive varicosities in the cell body layer and neural sheath of the snail, Helix pomatia, ganglia: an electron microscopic immunocytochemical study. Neuroscience 42: 583-591.

Elekes, K., and D. R. Nässel. 1990. Distribution of FMRFamide-like immunoreactive neurons in the central nervous system of the snail Helix pomatia. Cell Tissue Res. 262: 177-190.

Elekes, K., E. E. Voronezhskaya, L. Hiripi, M. Eckert, and J. Rapu. 1996. Octopamine in the developing nervous system of the pond snail, Lymnaea stagnalis L. Acta Biol. Hung. 47: 73-87.

Entz, G., and O. Sebestyén. 1942. Life in Lake Balaton. Királyi Magyar Természettudományi Társulat, Budapest (in Hungarian), 366 pp.

Filla, A., L. Hiripi, and K. Elekes. 2009. Role of the aminergic (serotonin and dopamine) systems in the embryogenesis and different embryonic behaviors of the pond snail, Lymnaea stagnalis. Comp. Biochem. Phvsiol. C Toxicol. Pharmacol. 149: 73-82.

Fong, P. P. 1998. Zebra mussel spawning is induced in low concentrations of putative serotonin reuptake inhibitors. Biol. Bull. 194: 143-149.

Gillette, R. 2006. Evolution and function in serotonergic systems. Integr. Comp. Biol. 46: 838-846.

Glebov, K., E. E. Voronezhskaya, M. Y. Khabarova, E. Ivashkin, L. P. Nezlin, and E. G. Ponimaskin. 2014. Mechanisms underlying dual effects of serotonin during development of Helisoma trivolvis (Mollusca). BMC Dev. Biol. 14: 14.

Goldberg, J. I., N. K. Koehncke, K. J. Christopher, C. Neumann, and T. J. Diefenbach. 1994. Pharmacological characterization of a serotonin receptor involved in an early embryonic behavior of Helisoma trivolvis. J. Neurobiol. 25: 1545-1557.

Hadfield, M. G. 2011. Biofilms and marine invertebrate larvae: what bacteria produce that larvae use to choose settlement sites. Annu. Rev. Mar. Sci. 3: 453-470.

Hadfield, M. G., E. A. Meleshkevitch, and D. Y. Boudko. 2000. The apical sensory organ of a gastropod veliger is a receptor for settlement cues. Biol. Bull. 198: 67-76.

Haszprunar, G., L. Salvini-Plawen, and R. M. Rieger. 1995. Larval planktotrophy: a primitive trait in the Bilateria? Acta Zool. 76: 141154.

Haszprunar, G., S. Friedrich, A. Wanninger, and B. Ruthensteiner. 2002. Fine structure and immunocytochemistry of a new chemosensory system in the Chiton larva (Mollusca: Polyplacophora). J. Morphol. 251: 210-218.

Hay-Schmidt, A. 1995. The larval nervous system of Polygordius lacteus Schneider 1868 (Polygordiidae, Polychaeta): immunocytochemical data. Acta Zool. 76: 121-140.

Hay-Schmidt, A. 2000. The evolution of the serotonergic nervous system. Proc. R. Soc. Lond. Biol. Sci. B 267: 1071-1079.

He, J., Q. J. Feng, and C. H. Ke. 2015. Embryonic and larval development of the invasive biofouler Mytilopsis sallei (Récluz, 1849) (Bivalvia: Dreissenidae). J. Molluscan Stud. 82: 23-30.

Hegedüs, E., J. Kaslin, L. Hiripi, T. Kiss, P. Panula, and K. Elekes. 2004. Histaminergic neurons in the central and peripheral nervous system of gastropods (Helix, Lymnaea): an immunocytochemical, biochemical, and electrophysiological approach. J. Comp. Neurol. 475: 391405 . 
Hernádi, L., K. Elekes, and S. Rózsa. 1989. Distribution of serotonincontaining neurons in the central nervous system of the snail Helix pomatia. Cell Tissue Res. 257: 313-323.

Ivashkin, E. G., M. Y. Khabarova, and E. E. Voronezhskaya. 2012. Serotonin transport and synthesis systems in invertebrate early development: functional analysis on a bivalve model. Acta Biol. Hung. 63(suppl.): $217-220$.

Ivashkin, E. G., M. Y. Khabarova, V. Melnikova, L. P. Nezlin, O. Kharchenko, E. E. Voronezhskaya, and I. Adameyko. 2015. Serotonin mediates maternal effects and directs developmental and behavioral changes in the of snails. Cell Rep. 12: 1144-1158.

Kemenes, K., K. Elekes, L. Hiripi, and P. R. Benjamin. 1989. A comparison of four techniques for mapping the distribution of serotonin and serotonin-containing neurons in fixed and living ganglia of the snail, Lymnaea. J. Neurocytol. 18: 193-208.

Kempf, S. C., G. V. Chun, and M. G. Hadfield. 1992. An immunocytochemical search for potential neurotransmitter in larvae of Phestilla sibogae (Gastropoda, Opistobranchia). Comp. Biochem. Physiol. 101: 299-305.

Kempf, S. C., L. R. Page, and A. Pires. 1997. Development of serotoninlike immunoreactivity in the embryos and larvae of nudibranch mollusks with emphasis on the structure and possible function of the apical sensory organ. J. Comp. Neurol. 386: 507-528.

Koolakovsky, E. E., and L. P. Phlyachinskaya. 1993. Formation of elements of the regulatory systems during larval development of Mytilus edulis. Zool. Zh. 72: 20-28 (in Russian).

Koshtoyants, K. S., G. A. Buznikov, and B. N. Manukhin. 1961. The possible role of 5-hydroxytryptamine in the motor activity of embryos of some marine gastropods. Comp. Biochem. Physiol. 3: 20-26.

Koss, R., T. J. Diefenbach, S. Kuang, S. A. Doran, and J. I. Goldberg. 2003. Coordinated development of identified serotonergic neurons and their target ciliary cells in Helisoma trivolvis embryos. $\underline{\text { J. Comp. }}$ Neurol. 457: 313-325.

Kreiling, J. A., K. Jessen-Eller, J. Miller, R. F. Seegal, and C. L. Reinisch. 2001. Early development of the serotonergic and dopaminergic nervous system in Spisula solidissima (surf clam) larvae. Comp. Biochem. Physiol. A Mol. Integr. Physiol. 130: 341-351.

Kristof, A., and A. Klussmann-Kolb. 2005. Neuromuscular development of Aeolidiella stephanieae Valdéz, (Mollusca, Gastropoda, Nudibranchia). Front. Zool. 7: 5.

Kuang, S., and J. I. Goldberg. 2001. Laser ablation reveals regulation of ciliary activity by serotonergic neurons in molluscan embryos. $\mathrm{J}$. Neurobiol. 47: 1-15.

Lacalli, T. C. 1984. Structure and organization of the nervous system in the trochophore larva of Spirobranchus. Philos. Trans. R. Soc. Lond. Biol. Sci. B 306: 79-135.

Leise, E. M., and L. B. Cahoon. 2012. Neurotransmitters, benthic diatoms and metamorphosis of a marine snail. Pp. 1-43 in Snails: Biology, Ecology and Conservation, E. Hämäläinen and S. Järvinen, eds. Nova Science, Hauppauge, NY.

Leise, E. M., K. Thavaradhara, N. R. Durham, and B. E. Turner. 2001. Serotonin and nitric oxide regulate metamorphosis in the marine snail Ilyanassa obsoleta. Am. Zool. 41: 258-267.

Leise, E. M., J. T. Washburn, J. G. Long, B. Bridgewater, and N. Shah. 2014. Acidic seawater can promote metamorphosis in the marine mud snail Ilyanassa obsoleta. J. N. C. Acad. Sci. 130: 64-70.

López-Vera, E., M. B. Aguilar, and E. P. Heimer de la Cotera. 2008. FMRFamide and related peptides in the phylum Mollusca. Peptides 29: 310-317.

Lovell, S. J., S. F. Stone, and L. Fernandez. 2006. The economic impacts of aquatic invasive species: a review of the literature. Agric. Resour. Econ. Rev. 35: 195-208.

Mackie, G. L. 1991. Biology of the exotic zebra mussel, Dreissena polymorpha, in relation to native bivalves and its potential impact in Lake St-Clair. Hydrobiologia 219: 251-268.
Marois, R., and T. J. Carew. 1997. Ontogeny of serotonergic neurons in Aplysia californica. J. Comp. Neurol. 386: 477-490.

Moroz, L. L., L. C. Sudlow, J. Jing, and R. Gillette. 1997. Serotoninimmunoreactivity in peripheral tissues of the opisthobranch molluscs Pleurobranchaea californica and Tritonia diomedea. J. Comp. Neurol. 382: $176-188$.

Naef, A. 1928. Die Cephalopoden. Fauna e Flora del Golfo di Napoli, Monografia della Stazione Zoologica di Napoli, vol. 35. Friedländer, Berlin.

Nässel, D. R. 1988. Serotonin and serotonin-immunoreactive neurons in the nervous system of insects. Prog. Neurobiol. 30: 1-85.

Nässel, D. R. 1996. Neuropeptides, amines and amino acids in an elementary ganglion: functional and chemical anatomy of the unfused abdominal ganglion. Prog. Neurobiol. 48: 325-420.

Newcombe, J. M., D. J. Fickbohm, and P. S. Katz. 2006. Comparative mapping of serotonin-immunoreactive neurons in the central nervous systems of nudibranch molluscs. J. Comp. Neurol. 499: 485-505.

Nezlin, L. P., and E. E. Voronezhskaya. 2003. Novel, posterior sensory organ in the trochophore larva of Phyllodoce maculata (Polychaeta). Proc. R. Soc. Lond. Biol. Sci. B 270: 159-162.

Nielsen, C. 1995. Animal Evolution: Interrelations of Living Phyla. Oxford University Press, Oxford.

Nielsen, C. 1998. Origin and evolution of animal life cycles. Biol. Rev. Camb. Philos. Soc. 73: 125-155.

O'Neill, C. R. J. 1997. Economic impact of zebra mussels: results of the 1995 National Zebra Mussel Information Clearinghouse study. Gt. Lakes Res. Rev. 3: 35-42.

Ospovat, M. F., E. E. Kulakovsky, and L. P. Flyachinskaya. 1989. Some aspects of detection of neurotransmitter systems in early development of the mussel Mytilus edulis. Proc. Zool. Inst. Acad. Sci. USSR 203: 76-83 (in Russian).

Page, L. R. 2002. Apical sensory organ in larvae of the patellogastropod Tectura scutum. Biol. Bull. 202: 6-22.

Page, L. R., and S. C. Parries. 2000. Comparative study of the apical ganglion in planktotrophic caenogastropod larvae: ultrastructure and immunoreactivity to serotonin. J. Comp. Neurol. 418: 383-401.

Redl, E., M. Scherholz, C. Todt, T. Wollesen, and A. Wanninger. 2014. Development of the nervous system in Solenogastres (Mollusca) reveals putative ancestral spiralian features. EvoDevo 5: 48.

Ruppert, E. E., and R. D. Barnes. 1994. Invertebrate Zoology, 6th ed. Saunders College Publishing, Fort Worth, TX.

Schindelin, J., I. Arganda-Carreras, E. Frise, V. Kaynig, M. Longair, T. Pietzsch, S. Preibisch, C. Rueden, S. Saalfeld, B. Schmid et al. 2012. Fiji: an open-source platform for biological-image analysis. Nat. Meth. 9: 676-682.

Serfőző, Z., K. Elekes, and V. Varga 1998. NADPH-diaphorase activity in the nervous system of the embryonic and juvenile pond snail, Lymnaea stagnalis. Cell Tissue Res. 292: 579-586.

Somlyódy, L., S. Herodek, and J. Fischer. 1983. Eutrophication of shallow lakes: modelling and management. The Lake Balaton case study. IIASA Collaborative Paper CP-83-703. IIASA, Laxenburg, Austria.

Sprung, M. 1993. The other life: an account of present knowledge of the larval phase of Dreissena polymorpha. Pp. 39-53 in Zebra Mussels: Biology, Impact, and Control, T. F. Nalepa and D. W. Schloesser, eds. Lewis, Boca Raton, FL.

Taylor, J. D., ed. 1996. Origin and Evolutionary Radiation of the Mollusca. Centenary Symposium of the Malacological Society of London. Oxford University Press, Oxford.

van der Gaag, M., G. van der Velde, S. Wijnhoven, and R. S. E. W. Leuven. 2016. Salinity as a barrier for ship hull-related dispersal and invasiveness of dreissenid and mytilid bivalves. Mar. Biol. 163: 147.

Vekhova, E., E. G. Ivashkin, O. Yurchenko, A. Chaban, V. A. Dyachuk, M. Y. Khabarova, and E. E. Voronezhskaya. 2012. Modulation of Mytilus trossulus (Bivalvia: Mollusca) larval survival and growth in culture. Acta Biol. Hung. 63(suppl.): 230-234. 
Vitellaro-Zuccarello, L., S. De Biasi, P. Bernardi, and A. Oggioní. 1991. Distribution of serotonin-, gamma-aminobutyric acid- and substance P-like immunoreactivity in the central and peripheral nervous system of Mytilus galloprovincialis. Tissue Cell 23: 261-70.

Voronezhskaya, E. E., and R. P. Croll. 2016. Mollusca: Gastropoda. Pp. 196-22 in Structure and Evolution of Invertebrate Nervous Systems, A. Schmidt-Rhaesa, S. Harzsch, and G. Purschke, eds. Oxford University Press, Oxford.

Voronezhskaya, E. E., and K. Elekes. 1993. Distribution of serotoninlike immunoreactive neurons in the embryonic nervous system of lymnaeid and planorbid snails. Neurobiology 1: 371-383.

Voronezhskaya, E. E., and K. Elekes. 1996. Transient and sustained expression of FMRFamide-like immunoreactivity in the developing nervous system of Lymnaea stagnalis (Mollusca, Pulmonata). Cell. Mol. Neurobiol. 16: 661-676.

Voronezhskaya, E. E., and K. Elekes. 2003. Expression of the FMRFamide gene encoded peptides by identified neurons in embryos and juveniles of the pulmonate snail Lymnaea stagnalis. Cell Tissue Res. 314: 297-313.

Voronezhskaya, E. E., L. Hiripi, K. Elekes, and R. P. Croll. 1999. Development of catecholaminegic neurons in the pond snail, Lymnaea stagnalis. I. Embryonic development of dopamine-containing neurons and dopamine-dependent behaviors. J. Comp. Neurol. 404: 285296.
Voronezhskaya, E. E., S. A. Tyurin, and L. P. Nezlin. 2002. Neuronal development in larval chiton Ischnochiton hakodadensis (Mollusca: Polyplacophora). J. Comp. Neurol. 444: 25-38.

Voronezhskaya, E. E., E. B. Tristin, and L. P. Nezlin. 2003. Neuronal development in larval polychaete Phyllodoce maculate (Phyllodocidae). J. Comp. Neurol. 455: 299-309.

Voronezhskaya, E. E., M. Y. Khabarova, and L. P. Nezlin. 2004. Apical sensory neurones mediate developmental retardation induced by conspecific environmental stimuli in freshwater pulmonate snails. Development 131: 3671-3680.

Voronezhskaya, E. E., L. P. Nezlin, N. A. Odintsova, J. T. Plummer, and R. P. Croll. 2008. Neuronal development in larval mussel Mytilus trossulus (Mollusca: Bivalvia). Zoomorphology 127: 97-110.

Walker, R. J. 1986. Transmitters and modulators. Pp. 279-485 in The Mollusca, A. O. D. Willows, ed. Academic Press, New York.

Walker, R. J., H. L. Brooks, and L. Holden-Dye. 1996. Evolution and overview of classical transmitter molecules and their receptors. Parasitology 113: 3-33.

Wanninger, A., and G. Haszprunar. 2003. The development of the serotonergic and FMRF-amidergic nervous system in Antalis entalis (Mollusca, Scaphopoda). Zoomorphology 122: 77-85.

Yaroslavtseva, L. M., and E. P. Sergeeva. 2010. Adaptability of the bivalve mollusk Crenomytilus grayanus larvae to short- and long-term changes of salinity. Bull. Russ. Far East Malacol. Soc. 14: 30-40. 